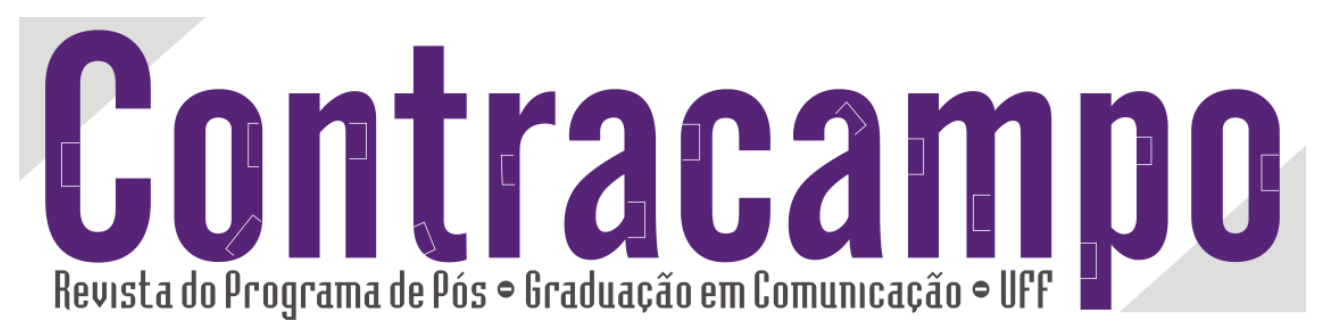

\title{
A Economia do Retweet: \\ Redes, Difusão de Informações e Capital Social no Twitter
}

\author{
The Retweet Economy: \\ Networks, Information Diffusion and Social Capital in Twitter
}

Raquel Recuero

raquel@raquelrecuero.com

Professora e pesquisadora do Programa de Pós Graduação em Letras da Universidade Católica de Pelotas (PPGL/UCPel).

Doutora em Comunicação e Informação.

Gabriela Zago

gabrielaz@gmail.com

Doutoranda do Programa de Pós-Graduação em Comunicação e Informação da Universidade Federal do Rio Grande do Sul

(PPGCOM/UFRGS).

${ }^{1}$ Trabalho apresentado no GT Comunicação e Cibercultura do XX Encontro da Compós, realizado na Universidade Federal do Rio Grande do Sul, em Porto Alegre, de 14 a 17 de junho de 2011.

\section{PPGCOM UFF}

Ao citar este artigo, utilize a seguinte referência bibliográfica

RECUERO, Raquel; ZAGO, Gabriela. A Economia do Retweet: Redes, Difusão de Informações e Capital Social no Twitter. In: Revista Contracampo, v. 24, n. 1, ed. julho, ano 2012. Niterói: Contracampo, 2012. Pags: 19-43.

\section{Edição 24/2012}

Ensaio temático "Sociabilidades em rede"

Contracampo

e-ISSN 2238-2577

Niterói (RJ), v. 24, n. 1, jul./2012.

www.uff.br/contracampo

A Revista Contracampo é uma revista eletrônica do Programa de PósGraduação em Comunicação da Universidade Federal Fluminense e tem como objetivo contribuir para a reflexão crítica em torno do campo midiático, atuando como espaço de circulação da pesquisa e do pensamento acadêmico. 


\section{Resumo}

Partindo da percepção do Twitter enquanto um micromensageiro capaz de ser apropriado como rede social e como canal de difusão de informações, o trabalho propõe-se a caracterizar uma "economia do retweet". Três casos são apresentados, nos quais os retweets foram mapeados na rede social, analisados e discutidos. Os resultados apontam para práticas que geram benefícios individuais e coletivos, nas quais o retweet atua como moeda de troca.

Palavras-chave: Redes sociais, difusão de informações, capital social.

\section{Abstract}

Based on the perception of Twitter as a micromessenger and as a tool capable of being appropriated as a social network and as a channel for information diffusion, this paper focus on the characterization of the "retweet economy". Three cases are presented, in which retweets were mapped on the social network, analyzed and discussed. Results point to practices that generate individual and collective benefits, in which the retweet acts as an exchange currency.

Keywords: Social networks, information diffusion, social capital. 


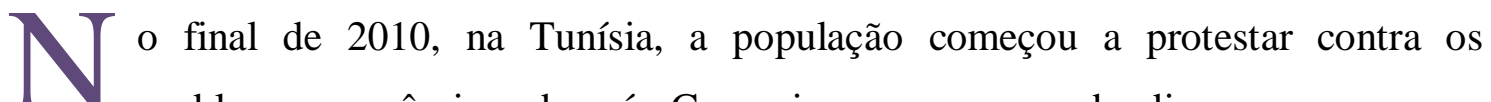
problemas econômicos do país. Com a imprensa censurada, diversas mensagens, com vídeos e imagens, foram postadas pelos tunisianos em sites de redes sociais. Os protestos culminaram com a renúncia do ditador Ben Ali no começo de 2011. Diante do papel proeminente exercido pelos sites de redes sociais ao divulgar a onda de protestos, o episódio chegou a ser denominado pela imprensa de "Twitter Revolution"1. Assim como o Twitter foi usado para ampliar o alcance dos protestos na Tunísia, inúmeros outros exemplos podem ser citados, em campos variados que vão de disputas simbólicas entre fãs à apropriação do canal como espaço para circulação jornalística. O que se observa, portanto, é a apropriação de uma ferramenta cujo foco estaria apenas na divulgação de mensagens quase pessoais (como apontava a questão original da ferramenta "o você está fazendo?") para um novo patamar, onde a informação é construída, trocada e valorada (como demonstra a mudança da questão para "o que está acontecendo?").

Exemplos como esses são significativos por apontar mudanças dos fluxos de informação na contemporaneidade, assinalados pelas apropriações de ferramentas como o Twitter. Como Benkler (2006: 376) afirma, "somos uma sociedade em rede agora indivíduos em rede, conectados uns aos outros" ${ }^{\prime 2}$. Rede esta que gera a infraestrutura para uma nova economia, chamada por ele de "economia da informação em rede".

Ferramentas como o Twitter $^{3}$ permitem a interconexão entre as pessoas, mantendo canais permanentes de circulação de informação: são as redes sociais amplificadas pela mediação do computador. De um modo especial, o Twitter tem sido apropriado para criação e manutenção de redes sociais que influenciam e são influenciadas pela difusão de informações. Essas práticas tomam forma principalmente através dos retweets (ou RTs ou retuítes). Retuitar uma informação é engajar-se em uma busca pelo capital social, gerando valores para o grupo e para o indivíduo (CHA et al, 2010). Assim, quais benefícios são gerados pelos RTs para as redes sociais e os atores

\footnotetext{
${ }^{1}$ http://migre.me/3RZSV Acesso em 12/12/2011.

2 Tradução de: "We are a networked society now-networked individuals connected with each other in a mesh of loosely knit, overlapping, flat connections".

${ }^{3} \mathrm{O}$ Twitter é uma ferramenta que proporciona a postagem de mensagens de até 140 caracteres para uma rede de seguidores, bem como a troca de mensagens entre usuários de forma pública (Replies) e privada (Messages). http://www.twitter.com
} 
no Twitter? Como pensar uma "economia do retweet" nas práticas de difusão de informações na ferramenta?

\section{Twitter, Capital Social e Difusão de Informações}

O estudo de como as informações são espalhadas dentro das redes sociais - e, mais especificamente, nas redes sociais na Internet - tem extensa literatura (ADAR e ADAMIC, 2005; CHA et al., 2010, XIAO et al., 2010 dentre outros). Isso porque a rede social online permite que os rastros das informações sejam rapidamente recuperados, $o$ que contribui para facilitar o estudo dessas práticas. O Twitter não é diferente. Para analisá-lo, a partir dessa perspectiva, traremos os conceitos de capital social e veremos a difusão de informações como parte das percepções de valor geradas pela rede social que apropria e utiliza a ferramenta.

\section{Capital Social}

Os valores gerados nos sites de rede social são frequentemente referidos como capital social (RECUERO, 2009). O capital social é um conceito focado nos valores associados a pertencer a uma rede social, mas sobre o qual há pouca concordância na literatura. Em geral, é referido como "recursos sociais" (LIN, 2001), acessados através das conexões que alguém possui em relação a um determinado grupo. Em si, portanto, o capital social constitui-se em um somatório de recursos aos quais o acesso só é possível através da rede social.

O capital social, enquanto forma de capital, é produto de investimento dos indivíduos em suas redes e da construção de valor nesses espaços. Lin (2001) explica que essa concepção prevê três elementos: (1) os recursos; (2) a estrutura social e (3) as ações. Os recursos são providos de valor em parte pela sua escassez e em parte pela cultura do próprio grupo. A estrutura social consiste nas hierarquias, regras e convenções, além das posições em relação aos recursos disponíveis. O terceiro elemento compreende as ações possíveis e as escolhas dos agentes capazes de mobilizar esses recursos. Por conta desses três elementos, vemos o capital social como um bem misto, que possui características públicas (conforme percebe PUTNAM, 2000) e privadas 
(conforme BURT, 1992). É público quando o investimento não beneficia apenas aquele que investe, mas a rede como um todo. É privado quando permite que os atores possam apropriar-se dos valores produzidos pela estrutura social. Por conta disso, o capital social também está associado à competição e às vantagens que podem ser obtidas. Assim, "pessoas mais bem conectadas usufruem de benefícios maiores" ${ }^{4}$ (BURT, 2000: 3). O capital social é, desse modo, um conceito metafórico, relacionado ao fato de que existem vantagens em pertencer a determinados grupos sociais, vantagens essas que podem ser apropriadas pelo grupo e/ou pelos atores. Os atores, nos grupos sociais, possuem motivações que os levam a determinadas ações, com vistas a investimentos que darão retornos esperados 5 . Nessa visão, predomina uma percepção vertical do capital social: trata-se de capital porque é constituído pelo controle que determinado ator ou grupo de atores tem sobre alguns recursos e pelo seu interesse em outros.

O capital social é um ingrediente essencial para a dinâmica de apropriação do Twitter, na medida em que é, também, um elemento essencial das redes sociais (RECUERO, 2009). O Twitter, como ferramenta que possibilita a criação e a complexificação de estruturas sociais, é capaz de gerar valores através de sua apropriação (JAVA et al, 2007). Assim, compreendemos o capital social como o conceito através do qual podemos discutir a estrutura que provê valor para as práticas no Twitter, como no caso do retweet.

\section{Difusão de Informação como Forma de Capital Social}

O capital social apresenta-se sob diversas formas (COLEMAN, 1988; BERTOLINI e BRAVO, 2004). Dentre essas formas, uma das mais comuns apontadas pela literatura é o acesso à informação. A estrutura das redes sociais altera e influencia a circulação de informações. Por exemplo, Granovetter (1973 e 1983), em seu já conhecido estudo, mostrou a importância dos laços sociais fracos para a circulação de informações nas rede sociais. Ele defende que, quanto maior a quantidade de laços

\footnotetext{
${ }^{4}$ Tradução de: "better connected people enjoy higher returns".

${ }^{5}$ A Teoria da Escolha Racional, pano de fundo de diversas perspectivas a respeito do capital social, inclusive a de Coleman (1988), prevê que as ações individuais são baseadas em cálculos de ganho e custo por todos os atores. Trata-se de uma teoria utilitarista, onde a racionalidade, assim, teria como fundamento a ideia de que os atores baseiam suas ações na perspectiva de maximizar seus ganhos. Embora tal visão seja considerada superada pelos teóricos da chamada "Racionalidade Limitada", por exemplo, ela é relevante na compreensão de parte da teoria proposta.
} 
fracos ${ }^{6}$ de alguém, maiores as chances de se receber informações diversificadas que podem representar oportunidades. O capital social relacionado à circulação de informações está também relacionado às formas através das quais essa informação se difunde nas redes e, portanto, com as ações dos indivíduos que podem repassar determinadas informações e outras não. Assim, a informação em si não é o valor, mas o acesso à mesma e o seu conteúdo o são.

Burt (1992: 18) vê os benefícios obtidos pelo acesso às informações a partir de três elementos: acesso, tempo e referências. $\mathrm{O}$ acesso relaciona-se diretamente com a obtenção de informações que sejam relevantes. O tempo relaciona-se com receber as informações rapidamente, ou antes do resto da rede social. As referências, por sua vez, fazem parte de um processo de filtragem (ou de ação) da rede social sobre as informações recebidas, referenciando e legitimando aquelas que são interessantes. Existe um alto custo para a obtenção de informações numa rede social, que não apenas exige atenção, mas igualmente envolvimento do ator na busca por fontes que sejam relevantes para a área de interesse. Assim, a ação de alguns em propagar determinadas informações rapidamente pode contribuir para a construção de valores coletivos para a rede social.

Os bens gerados pela circulação de informações na Internet têm sido vistos como bens públicos por diversos teóricos, na medida em que "o 'consumo' de informação por uma pessoa não diminui o uso que outra pessoa pode fazer dela"7 (KOLLOCK, 1999: online). Benkler (2006) vê a "informação em rede" como um novo espaço onde os bens públicos são produzidos e divididos. Lanham (2006) concorda, explicando que vivemos na era onde a informação é um recurso abundante. A escassez, entretanto, explica ele, está em outro recurso necessário para a difusão dessas informações: a atenção. A atenção é um bem limitado, dependente do tempo disponível e dos interesses de cada um. Wu e Huberman (2007) mostraram que a atenção também afeta a propagação de informações nas redes sociais e que, quanto mais uma determinada história se espalha, menos ela se torna relevante na rede. A atenção

\footnotetext{
${ }^{6}$ Laços fracos, na percepção de Granovetter, são aqueles que não carregam intimidade e proximidade entre os atores.

${ }^{7}$ Tradução de: “One person's 'consumption' of the information does not diminish another person's use of $i t^{\prime \prime}$.
} 
coletiva é reduzida pela ausência do fator novidade. Logo, se uma informação nova é colocada na rede, ela tende a receber mais atenção.

\section{Valores no Twitter}

Como o Twitter gera valor? Originalmente, apresentamos essa questão dentro da noção de apropriação. Ora, o Twitter é apenas uma ferramenta. Os valores construídos ali são valores construídos pela ação dos usuários em relação aos demais. São valores construídos, portanto, pelo uso, pela apropriação da ferramenta pela rede social. Enquanto isso, são valores dinâmicos, negociados dentro dos diferentes grupos que utilizam a ferramenta e estabelecidos na estrutura das redes sociais que são expressas ali (HUBERMAN, ROMERO \& Wu, 2009). A noção de valor, aqui, portanto, assemelha-se àquela discutida por Lin (2001): são construções sociais estabelecidas e negociadas pelos atores dentro da rede. É por isso que são, portanto, valores de capital social. Alguns trabalhos anteriores lançaram pequenos indícios em torno desta questão, que serão úteis para a discussão dos valores presentes no retweet.

$\mathrm{O}$ primeiro desses valores é o acesso à informação. Huberman, Romero e Wu (2009), estudando as redes sociais na ferramenta, descobriram que o número de trocas e conversações que aconteciam no sistema era muito pequeno em comparação com o número de seguidores e seguidos de cada rede. Com isso, os autores demonstraram que as conexões existentes no Twitter não necessariamente implicam em conexões baseadas em interação entre os participantes. Assim, as relações entre os atores nas redes no Twitter tendem a ser menos recíprocas e menos baseadas em interação. Seguir alguém, na ferramenta, significa ter acesso à informação publicada por aquele indivíduo e com quase nenhum custo, uma vez que não é necessária a interação como forma de manter o laço social.

Romero et al (2010), assim como Java et al (2007), no entanto, demonstram que a maior parte dos usuários da ferramenta é passivo, ou seja, não atua de forma a coletar e repassar informações. Aqueles que atuam nesse sentido estão filtrando as informações que serão repassadas à rede social. Para que a informação chegue a pontos mais distantes das redes no Twitter, é preciso que usuários ativos estejam dispostos a dispender tempo e atenção selecionando publicações para repassar. Assim, as redes 
sociais no Twitter também estão organizadas em torno das informações publicadas (ROMERO et al, 2010). A ação de alguns gera um benefício coletivo, que é a divulgação e a filtragem das informações.

Entretanto, o acesso à informação não é o único valor que aparece no Twitter. Cha et al. (2010) e Suh et al. (2010) demonstraram a influência como um dos valores mais relevantes nas dinâmicas no Twitter e um dos principais benefícios recolhidos com a prática de RTs. Para Cha et al. (2010), esse tipo de valor é conquistado com esforço cuidadoso e não tem uma relação direta com o número de seguidores. Ser influente é ser capaz de gerar efeitos e ações na rede social e resulta em determinados tipos de reputação (RECUERO e ZAGO, 2009). Portanto, a atividade daqueles usuários que filtram e disponibilizam as informações para a rede social não é o único valor que pode ser percebido no Twitter. Enquanto beneficiam a rede como um todo, esses atores também recolhem vantagens específicas, como a reputação e a capacidade de influência. Assim, temos bens públicos e privados que são construídos através do capital social no Twitter. Se de um lado, geram-se bens coletivos, de outro, geram-se bens privados. Mas como os retweets influenciam essas relações? Como vão atuar na economia que rege a difusão de informações na ferramenta?

\section{Abordagem metodológica}

Para discutir o retweet como uma forma de construir valores na rede social, precisamos antes discutir como ele se constitui e como aparece. A partir desta definição, escolhemos uma forma de mapear os RTs na rede, para avaliar a difusão de informações, e observamos o conteúdo dos retweets, para discutir suas relações com os valores identificados na literatura.

\section{O que são Retweets?}

O RT nasceu como uma convenção no Twitter, popularizada pelos usuários (BOYD, GOLDER e LOTAN, 2010), mas igualmente apropriada pela ferramenta. Inicialmente, o RT era realizado copiando-se o tweet de alguém e colocando-se a sigla 
"RT" na frente. A interface web do Twitter passou a incluir um botão para realizar "RT" no segundo semestre de $2010^{8}$.

O retweet pode aparecer das mais diversas formas e não há uma única sintaxe, como observaram boyd, Golder e Lotan (2010). De um modo geral, a prática consiste na reprodução de algo que alguém disse ou postou, com o crédito a quem originalmente publicou a mensagem, como exemplificado no Quadro 1.

\begin{tabular}{|c|l|}
\hline Tweet original & \multicolumn{2}{|c|}{ Retweet } \\
\hline schuschny: Manuel Castells fala & \multicolumn{1}{|c|}{ usuario: RT @ $\underline{\text { schuschny: Manuel }}$} \\
sobre Wikileaks $\underline{\text { http://nblo.gs/cOOWd }}$ & Castells fala sobre Wikileaks \\
& $\underline{\text { http://nblo.gs/cOOWd }}$ \\
\hline
\end{tabular}

Quadro 1. Sintaxe padrão de um retweet.

No exemplo, vemos a sintaxe mais característica dos retweets, onde há uma citação literal daquele indivíduo que originalmente publicou a informação acrescida da sigla RT e de uma menção ao usuário. No entanto, outras formas são possíveis. Por exemplo, na impossibilidade de reprodução de uma mensagem de forma integral, devido à limitação de 140 caracteres do Twitter, muitos reduzem a informação e modificam a citação e por vezes acrescentam outros marcadores de fonte, como "via @fulano". Quando o retweet é realizado através do botão de RT do próprio Twitter, a imagem daquele que fez o RT fica "escondida" na timeline de seus seguidores, aparecendo apenas o tweet original com um pequeno sinal no alto da imagem. Outras vezes, ainda, é possível observar a inclusão de comentários pessoais daquele que retuita, antes ou depois do retweet. Ele tem, portanto, formas diversas, mas um elemento essencial: a reprodução de uma determinada informação já publicada na rede social.

A limitação de caracteres do Twitter também traz importantes implicações para a prática de RT, que se refletem nas tensões entre atribuir a referência à fonte original ou a do último repasse, ou ao próprio fato de sinalizar ou não uma informação como sendo um retweet. De qualquer modo, reproduzir uma informação através de um retweet aparece como uma forma prática de dar visibilidade a uma determinada discussão, uma vez que a informação já foi previamente adicionada à rede por algum

\footnotetext{
${ }^{8}$ Antes disso, a maior parte dos "clientes" do Twitter (aplicativos utilizados para acessar o Twitter fora de sua interface "web", como por exemplo, o Twihrl) já incluia modos mais automáticos de retuitar.
} 
outro usuário, e cabe àquele que retuíta o papel de filtrá-la e contribuir para reverberá-la também entre diversas redes.

\section{Abordando os Retweets}

Para abordar o funcionamento do RT no Twitter e seu impacto nas redes sociais, escolhemos fazer um estudo com um foco multimetodológico, com elementos qualitativos e quantitativos de três casos de retuítes escolhidos de forma arbitrária. Inicialmente, para cada caso, foi realizada uma busca prévia no próprio Twitter, de modo a perceber se havia RTs e como os RTs aconteciam. A escolha se baseou em dois requisitos: 1) Ter uma URL gerada no migre.me ${ }^{9}$ e 2) Aparecer no top RTs do Migre.me. O primeiro requisito foi delimitado porque cada URL criada no encurtador é única e, uma vez criada por alguém, demarca uma informação original, pois apenas pode ser copiada ${ }^{10}$. O segundo requisito aconteceu para que conseguíssemos observar o "caminho" do RT na rede, de forma a compreender como ele se espalha.

Escolhemos mapear os RTs pela URL apenas porque, como já foi discutido por outros pesquisadores (vide BOYD, GOLDER e LOTAN, 2010), o RT aparece de formas diversas e é bastante difícil encontrar uma sintaxe que seja universal. Entretanto, é possível mapear a informação original pela URL, uma vez que essa só pode ser criada pelo autor do tweet original. Para fazer a coleta dos RTs foi utilizado o programa NodeXL ${ }^{11}$. Foram coletados tweets a partir da busca do Twitter pelo link escolhido. À época do estudo, essa busca tinha a limitação (imposta pelo Twitter) de apenas conseguir recolher tweets de até sete dias. Assim, através do crawler ${ }^{12}$ foram recolhidos 1000 atores que mencionaram o link, as referências que foram feitas (por exemplo, quais outros atores foram citados) e suas relações de seguidores, além de todos os retweets realizados.

\footnotetext{
${ }^{9}$ O Migre.me (http://www.migre.me) é um encurtador de URL. Esses sistemas criam uma máscara para a URL que visa reduzir o número de caracteres da mesma e é especialmente utilizada por usuários do Twitter e de outros serviços onde as postagens têm um número de caracteres limitados.

${ }^{10} \mathrm{Ou}$ seja, não pode ser deduzida por alguém que não teve contato com a mensagem original ou com uma de suas derivações.

${ }^{11} \mathrm{O}$ NodeXL funciona como um plug-in para o Microsoft Excel e é distribuído de forma gratuita a quem detém o software original. Foi desenvolvido para analisar e realizar a coleta de dados de redes sociais, e contém um crawler que permite que sejam buscadas informações em alguns sites de rede social específicos, como o Twitter e o Flickr. Outras informações: http://nodexl.codeplex.com/.

${ }_{12}$ Um crawler é um programa que percorre a internet, de forma sistemática e autônoma, à procura de dados específicos determinados pelo construtor da ferramenta.
} 
Após a coleta de dados, as redes foram analisadas por menções (foram contabilizadas todas as referências e montada a rede) e por seguidores. Para observar essas redes, foi utilizada a abordagem metodológica da Análise de Redes Sociais (WASSERMAN e FAUST, 1994; SCOTT, 2000). A análise de redes sociais propõe uma série de métricas para mapeamento das redes, que são observadas a partir de suas relações estruturais entre nós e conexões. No caso, para o mapeamento das redes, foram utilizadas as conexões de citação (rede de referências) e de seguidores (quais seguidores fizeram RT). Para este trabalho, foram calculadas:

- a distância geodésica média e máxima entre os nós da rede: Representa a "distância" do nó que fez o RT ao ego (autor do RT original). Quanto mais distante, mais longe a informação "viajou". A distância geodésica máxima mostra a maior distância atingida na difusão de informação e a média, aquela onde a maior parte dos RTs chegou.

- os números de componentes presentes: Representam os sub-grafos que não estão conectados entre si, ou seja, que estão separados dos demais ou isolados. Quanto maior o número de componentes, menos clusterizada ${ }^{13}$ é uma rede. Essa medida é útil para que se verifique se uma determinada informação aparece mais dentro de um grupo ou espalha-se mais através dos grupos.

Finalmente, buscando compreender melhor o que acontecia em cada rede de RTs, foram também analisadas as mensagens coletadas, com relação à sua forma, às referências feitas e ao seu sentido geral (a mensagem busca apenas informar ou há também um comentário?).

Esse método, no entanto, possui limitações. A primeira delas é a impossibilidade de se coletar todos os RTs que apareceram para cada informação, devido a limitações de tempo ${ }^{14}$, e aquelas impostas pelo próprio Twitter $^{15}$ e pelo próprio NodeXL ${ }^{16}$. Em redes muito grandes, como em um dos casos estudados, essas limitações podem influenciar os resultados (como discutiremos adiante). Entretanto, acreditamos

\footnotetext{
${ }^{13}$ Um cluster é um conjunto de nós bastante interconectado em uma rede. Diz-se que uma rede é pouco clusterizada quando poucos de seus nós estão interconectados.

${ }^{14}$ A passagem do crawler é bastante demorada; por isso, o estudo limitou-se a três casos.

15 O Twitter impõe limitações da quantidade de dados que alguém pode obter no sistema em um determinado espaço de tempo.

${ }^{16}$ Há um limite de operações possíveis de ser realizadas, como por exemplo, apenas mil atores podem ser mapeados por vez.
} 
que também é possível obter-se dados bastante relevantes, os quais podem iluminar parte da discussão dos valores e práticas de RT.

\section{Análise: Mapeando RTs}

Para obter mais pistas a respeito do espalhamento dos RTs e dos valores gerados, monitoramos o espalhamento de informações em três casos, que serão apresentados a seguir e discutidos a partir do referencial teórico apresentado.

\section{Caso Ministério da Saúde}

O primeiro caso escolhido foi o mapeamento de um tweet do Ministério da Saúde (Figura 1) de 14 de janeiro de 2011, que conclamava profissionais da saúde que quisessem ajudar na tragédia das chuvas da região serrana do Rio de Janeiro a se cadastrarem como voluntários.

minsaude Ministério da Saúde

Se vocé é profissional de saúde e quer ajudar, como voluntário, os sobreviventes do RJ, clique aqui: http://migre.me/3DQNO 14 Jan

Figura 1. Tweet originalmente mapeado.

Na rede analisada neste trabalho, o tweet foi repassado 539 vezes, por 453 nós. O Ministério da Saúde (ego central, em vermelho nas imagens, 33988 seguidores ${ }^{17}$ ), recebeu 415 citações, das quais 277 eram RTs da mensagem original, e 13 contêm pequenas modificações. Dessas, 290 citavam apenas a fonte original e 249 citavam além do autor, outra fonte. Destes, 158 tweets continham menções a apenas dois autores. 124 não citavam o autor original da mensagem.

\footnotetext{
${ }^{17}$ Dados de 16 de janeiro de 2010.
} 


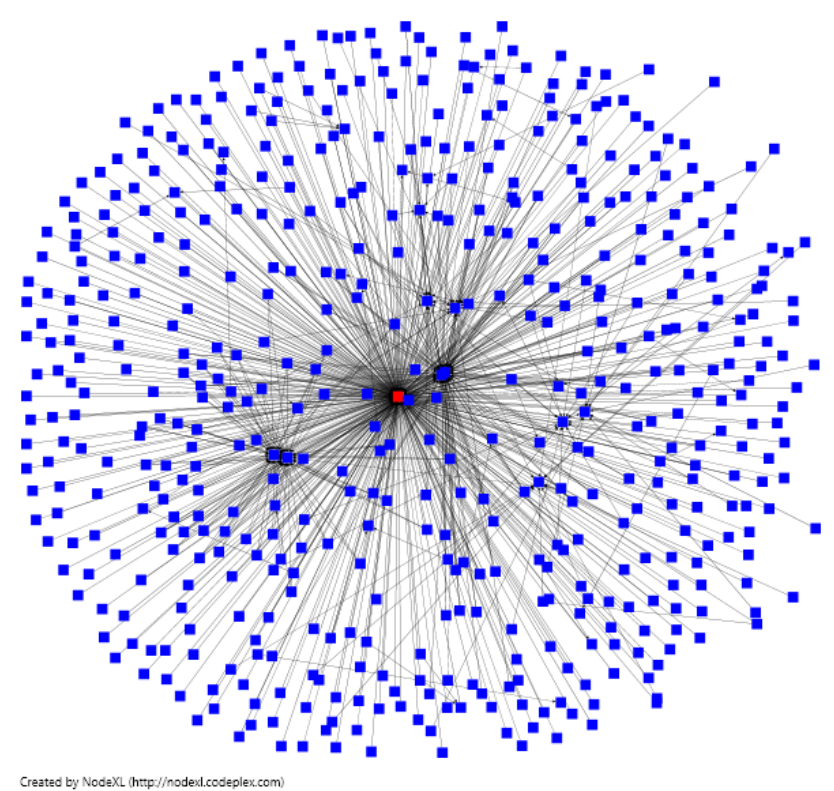

Figura 2. Rede de menções do tweet.

Essa rede de citações ou menções (Figura 2) mostra que parece existir uma forte relação entre ter sido o primeiro a escrever a mensagem e ser retuitado ou receber o crédito por ela. Entretanto, no caso do tweet analisado, a referência parece também ter como função dar credibilidade para a informação, uma vez que a fonte original empresta tal valor. Os tweets que não citavam só a fonte original mencionavam também uma fonte secundária. Isso parece indicar que a quantidade de referências tende a ser reduzida, mesmo quando a mensagem atinge uma distância maior na rede. Por exemplo, vimos que a mensagem atingiu 11 graus como distância geodésica máxima. Entretanto, olhando os tweets coletados não encontramos nenhum que fizesse 11 referências. A média foi de 3,69 graus. Entretanto, a expressiva maioria dos retweets mapeados fazia referência apenas ao autor original ou ao autor e mais outra fonte. Esse corte de referências provavelmente acontece para que a mensagem não sofra prejuízos diante da limitação do número de caracteres do Twitter. Além disso, o fato de que muitos preferem indicar a fonte original e não aquela por onde receberam a mensagem também é uma pista importante. Esses elementos podem indicar, por exemplo, que menções demais dificultam a visibilidade da informação e do autor do retweet, reforçando a ideia de que há uma competição pela atenção e pela visibilidade (LANHAM, 2006). 


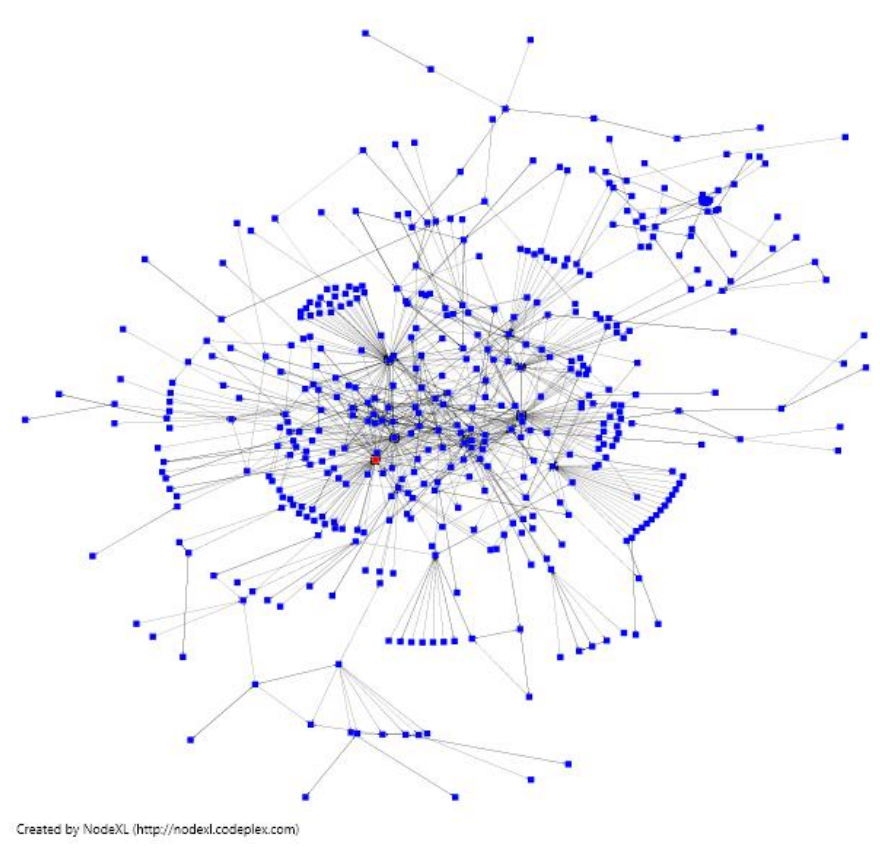

Figura 3. Rede de seguidores.

Observamos também que uma grande parte dos tweets simplesmente reproduzia a informação, sem fazer comentários ${ }^{18}$. Na rede de seguidores (Erro! Fonte de referência não encontrada.), observamos como a participação na campanha pouco tem a ver com seguir o autor do tweet original. Vemos que a maior parte daqueles que deram o RT o fizeram porque viram na rede de outros e não porque participavam da rede original. Ainda, a publicação do tweet por um membro da rede não invalida, também, a sua publicação por outros.

O RT, neste caso, também pode ser visto como parte de uma campanha virtual. Isso porque o retweet em questão tem uma função social. Ao fazer o retuíte, os atores parecem estar engajados na campanha. Embora nem todos sejam profissionais de saúde, muitos daqueles que o são poderiam receber a informação à medida que ela chegasse mais longe na rede. Há, portanto, dois tipos de benefícios. O bem público da difusão da informação é que esta chegue o mais longe possível na rede, pois assim serão maiores as chances de atingir os profissionais de saúde para que se cadastrem. Por outro lado, sua divulgação não apenas dá visibilidade a quem repassou, mas igualmente indica

\footnotetext{
${ }^{18}$ Aqueles que faziam optavam por algo simples, como por exemplo: "Vamos lá, enfermeiros, médicos que estão aposentados ou querem colaborar com os sobreviventes do RJ, clique aqui: http://migre.me/3DQN0".
} 
compromisso. Por isso, o espalhamento dela é também um apoio e uma participação e não apenas uma indicação.

$\mathrm{Na}$ rede de seguidores temos um total de 21 componentes. Ou seja, é uma rede relativamente desconectada, com atores bastante distantes do Ministério da Saúde. Podemos observar que a mensagem atinge pontos mais distantes na rede e vemos, também, que há um espalhamento maior da informação entre pessoas que seguem a mesma fonte. Assim, pode-se dizer que a mensagem tende a espalhar-se mais por diferentes laços (e não apenas pelos fracos ou pelos buracos estruturais conforme argumentam Granovetter, 1983 e Burt, 1992). Ou seja, neste caso, retuitar a mensagem dentro da rede, mesmo que alguém já tenha feito o RT, não parece reduzir tanto o valor da informação - o fator "novidade" (WU e HUBERMAN, 2007) já é reduzido. Isso talvez aconteça pelo caráter "campanha" da informação, que gera valores diferentes para a difusão de informação. Do mesmo modo, os sucessivos RTs da mesma informação também aumentam as chances de visibilidade da própria, atuando diretamente na competição pela atenção (ROMERO et al, 2010) e demonstrando o poder de influência daqueles que conseguem mobilizar suas redes na divulgação da mensagem (CHA et al., 2010).

\section{Caso da Mudança do Zodíaco}

Um segundo caso mapeado foi um retweet que comentava a notícia da suposta mudança dos signos zodiacais e cujo link apontava para uma matéria específica vinculada na Folha.com ${ }^{19}$. O link mapeado foi primeiro publicado por @HugoGloss (Figura 4). Foram coletados 922 RTs, com 1313 menções ou referências. A mensagem foi postada no dia 13 de janeiro e foram coletados retweets realizados entre os dias 13 e 16 de janeiro.

\section{HugoGloss: Mudaram os signos??OIIII????? http://migre.me/3CFDN 70.5 3 days ago via web. Reply. View Tweet}

Figura 4. Tweet originalmente mapeado

\footnotetext{
19 http://www1.folha.uol.com.br/ilustrada/860078-astronomo-defende-novo-zodiaco-veja-se-o-seu-signomudou.shtml. [Acesso dia 05/01/2012]
} 
A maior parte dos usuários que retuitou citou o autor original da mensagem (Figura 4). Foram 289 RTs exatamente iguais ao tweet original (apenas acrescidos de RT) com um total de 902 fazendo menção ao usuário que primeiro fez o retweet. Uma pequena quantidade (20) de RTs referenciava apenas outra pessoa apesar de conter a mesma informação. A maioria das mensagens (633), entretanto, continha comentários pessoais daqueles que faziam o RT, quase sempre com relação a como seu signo ficaria ou com alguma resposta pessoal à mensagem divulgada por outra pessoa. Ou seja, a maior parte dos retweets coletados preocupava-se em fazer uso da URL e da indicação

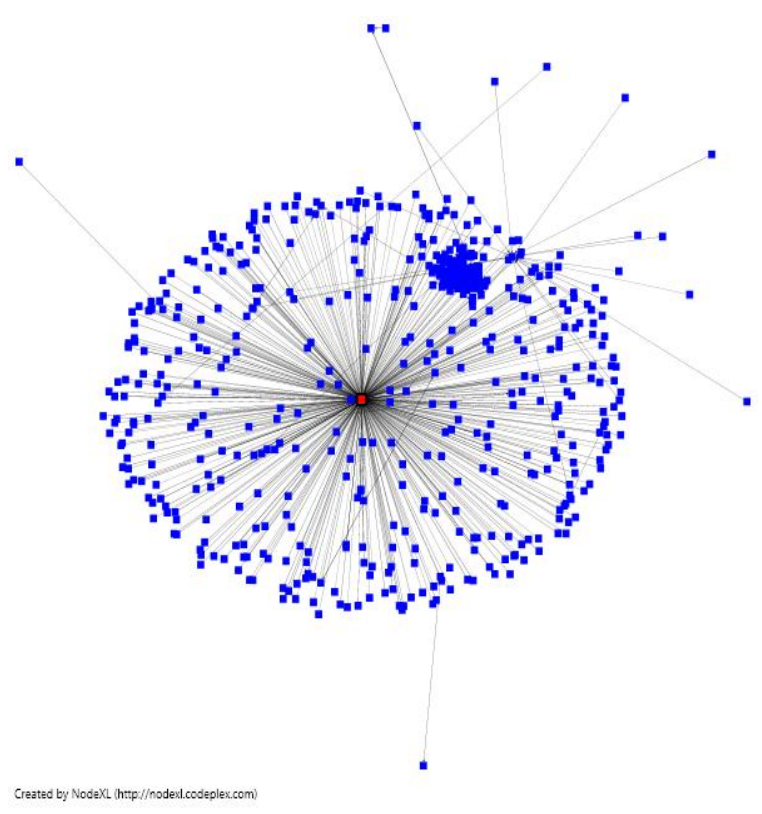
como parte de uma conversa com os seguidores. O link, no caso, tinha uma função não apenas informativa, mas igualmente de dar contexto ao comentário e expressar uma opinião.

Figura 5. Rede de menções.

Figura 6. Rede de seguidores

A rede de seguidores (Figura

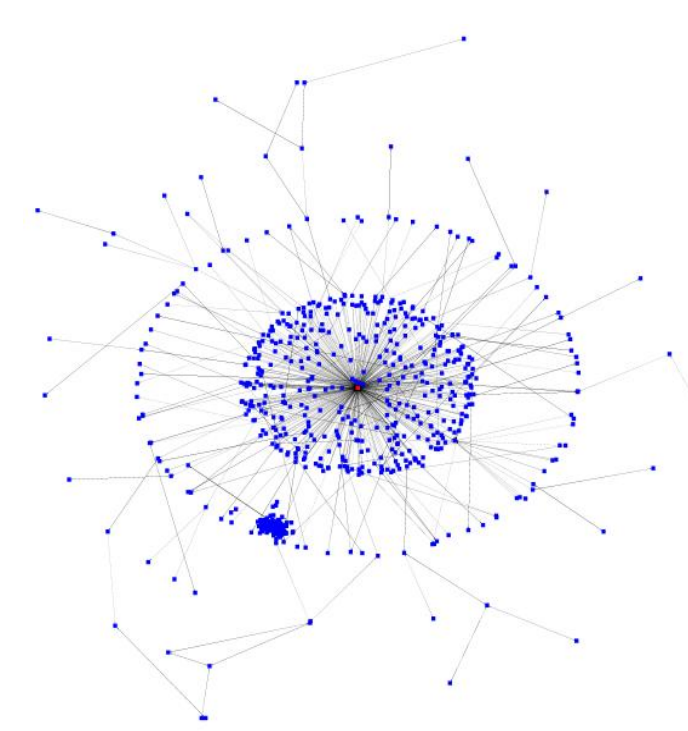

tinha uma distância geodésica média de 2,66 graus e máxima de 10 graus. Foram mapeados também 683 nós e 802 conexões, com um total de 77 componentes. O número de componentes indica a desconexão do grafo, ou seja, quanto maior, menos clusterizada é a rede. Entretanto, o número de componentes também pode dar uma falsa impressão de desconexão quando se mapeia um conector (no caso, o usuário @HugoGloss tem 486.615 seguidores). Como a quantidade de seguidores é muito grande, o crawler provavelmente não conseguiu ir muito além dos primeiros graus de separação devido à limitação do número de atores a ser mapeados. Entretanto, é 
interessante observar que a informação originalmente colocada não só não andou longe na rede (10 graus), mas foi também difundida em redes mais próximas do autor da mensagem (média de 2,66 graus). No caso, vemos que uma grande quantidade de retweets aconteceu, exatamente, dentro da própria rede de seguidores do autor da mensagem original e entre seus seguidores, o que poderia reforçar o caráter dialógico do RT .

Dentre os 922 tweets mapeados, 252 apenas eram retuítes sem nenhum tipo de adição ou mudança, citando unicamente o autor da mensagem original. Dos demais, apenas 146 citavam o RT original, mas a maioria com algum comentário pessoal antes da mensagem retuitada. Os restantes citavam outros autores ou apenas o link. Talvez aqui tenhamos o fato de que a novidade (WU e HUBERMAN, 2007) não seja tão importante a ponto de merecer ser citada mesmo que outros já o tenham feito na sua rede, ou seja, acrescida de valor pelos comentários realizados pelos atores. Muitos dos RTs mapeados, por exemplo, citavam qual seria o "novo" signo do autor da mensagem e o que este pensava disso ${ }^{20}$. Vê-se, portanto, um forte caráter de personalização dos retweets como forma de acrescentar valor ao que foi difundido. Do mesmo modo, também vê-se um forte potencial de caráter dialógico uma vez que vários retweets são respostas a outros ${ }^{21}$. Ambos os benefícios gerados pelo retweet são mais privados do que públicos. Retuitar a mensagem em questão pode gerar identificação, conversação e mesmo gerar novas conexões, todas apropriações privadas do capital social. O bem público seria relacionado com a possível clusterização da rede, o que possibilitaria a circulação de outras informações. Ao mesmo tempo, o RT da mensagem gera influência e reputação para o autor original (que é mais visível do que no caso anterior, uma vez que a maioria dos retweets continha referência a ele).

\section{Caso da Promoção Webcelebbrasil}

Outro caso escolhido para mapear foi uma promoção do Webcelebrasil (Figura 7). $\mathrm{O}$ jogo ${ }^{22}$, que simula um Big Brother virtual e busca escolher "a próxima celebridade

\footnotetext{
${ }^{20}$ Por exemplo: "Tô passada q virei gêmeos. Não creio nisso! RT @HugoGloss: Mudaram os signos??OIIII????? http://migre.me/3CFDN".

${ }^{21}$ Por exemplo: "@usuario Tá tudo doido Su, até nosso signo mudou... tá sabendo? rsrs eu era gêmeos agora sou touro! http://migre.me/3CFDN".

${ }^{22}$ http://webcelebbrasil.tumblr.com/webceleb [Acesso 12/12/2011]
} 
da Internet", usou o Twitter para sortear um netbook aos seus seguidores. A mensagem foi postada no dia 14 de janeiro e foi mapeada entre os dias 14 e 17 do mesmo mês.

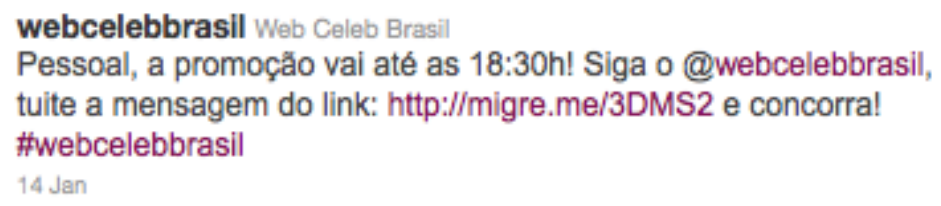

Figura 7. Tweet original

A partir do tweet original, foram coletados 664 RTs, com 3465 referências. A expressiva maioria dos RTs simplesmente repetia a mensagem original (399) realizando o RT através do botão do Twitter. Outra parte (137 tweets) repetia mensagens semelhantes da promoção que foram tuitadas subsequentemente pelo autor da mensagem original com um "RT" na frente (indicando, portanto, que foi um retuíte manual). Quinze tweets faziam breves e pequenos comentários do autor do retweet, de forma a personalizar a mensagem, mas também apenas referenciando o autor original ${ }^{23}$. Foram, assim, 551 tweets que referenciavam apenas o autor do primeiro tweet, 536 dos quais com uma repetição da mensagem original. Os 113 restantes referenciavam, também, outras pessoas no retuíte. Entretanto, também repetiam o RT original, apenas acrescido de um intermediário.

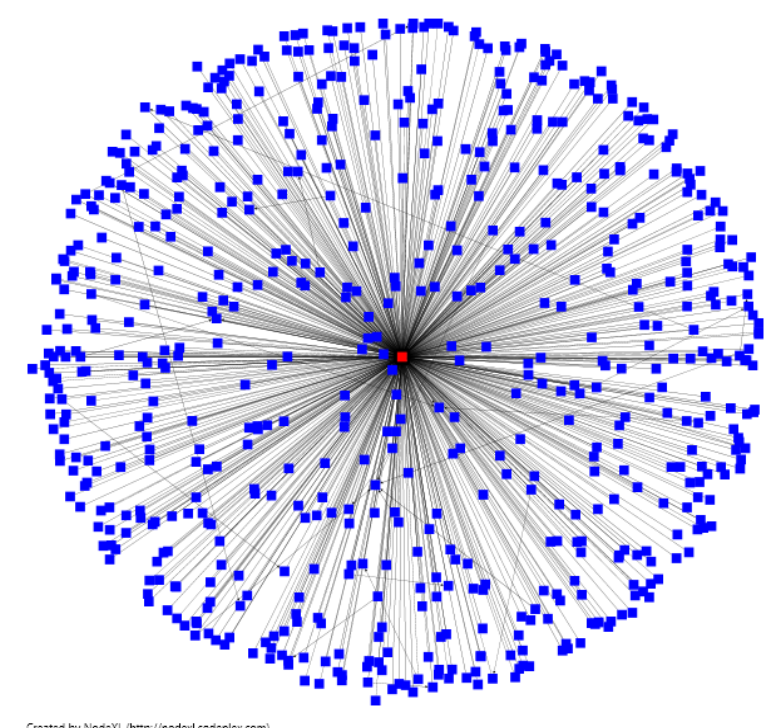

${ }^{23}$ Por exemplo: "Galera, quem acompanhar o @ webcelebbrasil e seguir concorre a um netbook CCE info/intel. http://migre.me/3DMS2 \#webcelebbrasil MOLEZINHA!". 
Figura 8. Rede de menções.

No mapa de menções (Figura 8), vê-se o autor do tweet original (em vermelho) e observa-se que todos os autores de RTs fizeram menção a ele (o que seria esperado, uma vez que citar o autor era parte da promoção).

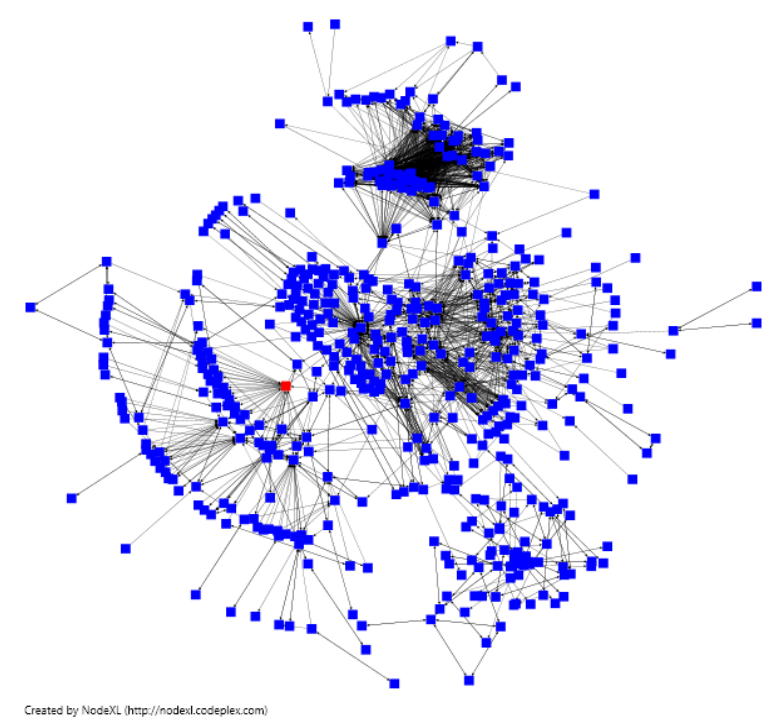

Figura 9. Rede de seguidores.

A rede de seguidores mapeada apresenta 501 nós e 2786 conexões, com 25 componentes mapeados (Figura 9). A distância geodésica máxima da difusão da informação nas redes foi de 9 graus e a média de 3,73 graus. Ou seja, vemos que houve uma tendência maior da mensagem original ser retuitada entre nós relativamente próximos na rede. $\mathrm{O}$ número de componentes é significativamente menor do que no caso anterior, o que também indica uma tendência de a informação propagar-se também dentro dos clusters e não apenas pelos laços mais fracos e pelos buracos estruturais (Figura 9). Ao contrário do caso anterior, os RTs não foram, em sua maioria, personalizados e construídos como forma de debater ou iniciar uma conversação. Apenas repetiam a mensagem original, talvez pelo próprio caráter do tipo de promoção proposta pelos autores da mensagem original. Nota-se, também, que o RT, por se constituir em uma participação direta na promoção, além de informar aos seguidores da mesma, mostra que a informação também espalhou-se por distâncias mais próximas (3,73 graus em média), atingindo um menor número de componentes. Isso também 
indicaria que a repetição da mensagem não implica numa perda de valor para a rede e nota-se que ela foi repetida de forma igual entre vários clusters. $\mathrm{O}$ benefício de divulgar a mensagem, que seria o de caráter público, é aquele de informar a rede de seguidores a respeito da promoção. Entretanto, também há um benefício privado que é aquele de concorrer à promoção. Além disso, também se torna visível para a rede social. Novamente, o fator novidade (WU e HUBERMAN, 2007) não parece atingir uma relevância maior.

\section{A Economia do Retweet}

Para discutir os valores presentes nas práticas de retweet, retomaremos a perspectiva de Burt (1992) a respeito dos benefícios obtidos pela difusão de informações que poderiam atuar no capital social. O primeiro valor de um retweet é aquele da referencialidade. Nas redes estudadas vimos que não há uma relação direta entre retuitar uma mensagem e seguir o autor original. Assim, percebe-se que o retweet é uma forma importante de visibilidade na rede, gerando crédito ao autor da mensagem, propagando seu nome e a informação a nós bastante distantes da rede e componentes que não estão diretamente conectados. Assim, ao fazer um retweet, geram-se duas referências para uma determinada informação: a daquele que originalmente publicou a informação e a daquele que fez o RT. Ambos recebem (embora em caráter diferente) visibilidade e crédito pela informação. Visibilidade porque, ao receber um RT, alguém torna-se visível a uma parte da rede social para a qual não estaria e ao mesmo tempo, recebe um voto de valor pelo conteúdo por aquele que fez o RT. Quem fala dá credibilidade a uma determinada informação e influencia a sua propagação, pois lhe empresta, também, valor. Como observamos nos casos especificados, ser o primeiro a publicar uma informação considerada relevante pela rede social rende um grau muito grande de visibilidade em lugares distantes da rede, através do retweet. Para muitos autores, essa visibilidade é também influência (CHA et al., 2010; ROMERO et al, 2010 e SUH et al, 2010). Vimos, nos três exemplos, que há uma tendência a suprimir autores anteriores ou intermediários. Essa prática parece estar diretamente relacionada com a competição pela referencialidade. Quanto mais distante do autor original e mais fontes citadas no RT, menores as chances de um novo retweet gerar menções para quem o fez. 
Retirando o "caminho" da mensagem, um novo RT pode ter mais chances de gerar menções também para quem o fez, mesmo que longe na rede.

O segundo valor de um retweet é o acesso. Quando alguém faz um RT, está repassando uma informação que acredita que sua rede ainda não tenha recebido. Está, portanto, provendo acesso a algo que considera relevante. Essa ação de filtragem coletiva mantém a informação circulando e a leva a lugares mais distantes na rede. Gera, portanto, um benefício público, coletivo, decorrente da estrutura da rede. Entretanto, como o retweet também possui referencialidade, ele também gera bens privados, pois a visibilidade dos atores que são retuitados pode gerar um número maior de seguidores, tipos diferentes de reputação e mesmo credibilidade. Assim, mesmo que os valores gerados pela difusão de informações sejam inicialmente bens públicos, eles também podem ser apropriados pelos indivíduos como bens privados, para construir valores específicos para esses atores. Vimos que a referencialidade, por exemplo, tende a ser reduzida para aqueles que não estão próximos a quem fez o RT original. Para acrescentar valor, muitos optam por fazer comentários pessoais, e mesmo incitar conversações. Isso aponta, também, para uma competição pela visibilidade gerada pelo acesso e pela referencialidade na rede (BURT, 1992). Também observamos que em muitos casos, os autores modificam as mensagens antes de fazer o RT, como uma forma de acrescentar um comentário pessoal ou um contexto. Isso pode "renovar" uma mensagem antiga, gerando comentários e respostas e, também, benefícios privados a seu autor. Aquele que faz um RT provê sua rede com uma informação que esta talvez não tivesse anteriormente, funcionando, também, como um filtro e provendo benefícios públicos.

O terceiro valor é o tempo. Ao fazer um RT, há uma possível aceleração da velocidade através da qual uma informação nova chega à rede social. O tempo tem uma relação direta com o fator novidade apontado por Wu e Huberman (2007), pois está relacionada com o fato de que o retweet provê à rede acesso a uma determinada informação que se supõe nova ${ }^{24}$. Vimos que a novidade nem sempre é requisito essencial para o retweet e que algumas informações parecem não perder valor quando divulgadas junto a redes mais conectadas. Apesar de a novidade ser certamente um fato que afeta as práticas de retweet, outros valores também podem emergir. No caso da

\footnotetext{
${ }^{24}$ Especialmente no caso dos retweets feitos a partir do botão retweet, os quais apenas são exibidos uma vez em cada timeline, ainda que mais de um contato tenha retuitado o mesmo tweet.
} 
promoção observada, o valor não era espalhar a informação. De fato, espalhá-la poderia reduzir as chances de obter o prêmio. Desse modo, os usuários tinham um motivo para não espalhá-la até o último minuto. Assim, o espalhamento da informação parece estar relacionado menos com o tempo e mais com o tipo de informação compartilhado. Entretanto, o tempo, no RT, é também um bem público (a informação chega mais rapidamente) e privado (aquele que inicialmente publicou a informação tende a receber mais RTs e ser mais visível).

Esses três benefícios aparecem de forma diferente conforme o tipo de RT. Cada uma dessas formas é capaz de enfatizar determinados valores e reduzir outros. E cada um desses benefícios também atua de forma diferente no capital social. A visibilidade, principal benefício privado do retweet é um bem gerado pela rede. Quanto mais RTs, mais visível é um determinado ator. Entretanto, é um bem escasso, pois depende da atenção (LANHAM, 2006), da distância daquele que publicou a informação original. Como vimos, o RT pode deixar autores visíveis até mesmo em pontos distantes da rede e pode gerar valores para os referenciados. Há, assim, uma competição pela visibilidade dentro do RT e entre os retuites, como ocorre nas mensagens do Twitter em geral (SUH et al, 2010). Aqueles mais comentados, e, portanto, mais difundidos, tendem a conseguir mais atenção. Vimos também que a informação tende a percorrer longos caminhos na rede. A distância geodésica máxima dos RTs analisados esteve em torno de 10 ou 11, o que é bastante distante do autor original, e o número de componentes atingido é igualmente alto (20-70), indicando a capacidade do RT de atingir redes diferentes.

\section{Apontamentos Finais}

O RT parece ser o principal "motor" da difusão de informações no Twitter, pois gera visibilidade para a informação e para a fonte que originalmente a publicou. $\mathrm{O}$ retweet tem efeitos sobre a rede e se utiliza dela para gerar valor. Neste caso, se observarmos os elementos do capital social (LIN, 2001), temos o recurso, que é a informação, a estrutura da rede, que permite o acesso a essa informação (no caso, as redes de seguidores no Twitter) e as ações que são tomadas para que o valor seja gerado (no caso, o retweet). $\mathrm{O}$ retweet é, portanto, uma das formas de gerar difusão e acesso às 
informações, conforme proposto por Coleman (1988). É ainda uma prática que originalmente não estava prevista na ferramenta, resultante, portanto, da apropriação e do uso da mesma (HONEYCUTT e HERRING, 2009). É, assim, um dos elementos pelos quais as redes sociais apropriam o Twitter, tornando-o uma ferramenta capaz de gerar valor.

O RT gera dois tipos de bens (COLEMAN, 1988): aqueles de caráter público, que consistem no acesso à informação e aqueles de caráter privado, decorrentes da hierarquia da rede em torno de quem publica e quem filtra a informação. Os bens privados são interdependentes dos bens públicos e, possivelmente, a principal motivação para que os atores engajem-se em práticas como o retweet, pois, como vimos, as ações individuais são guiadas pela busca de benefícios que são escassos (COLEMAN, 1988; BURT, 1992). O benefício público do Twitter, de outra sorte, poderia ser apenas um efeito das práticas de competição pelo capital social. O RT pode ser visto, assim, como uma moeda, capaz de gerar benefícios públicos e privados com base na estrutura da rede social explícita no Twitter. É também uma prática hierárquica, na medida em que centraliza referências e provê alguns com benefícios aos quais outros não têm acesso. A prática é capaz de gerar, como vimos, visibilidade de algumas informações sobre outras. Aquela que recebe mais RTs, por exemplo, torna-se mais visível e mais capaz de capturar a atenção do que a informação que não recebe ou recebe menos RTs. Com isso, aquele que faz o retweet também recebe algum tipo de atenção (especialmente nas práticas de retweet "manual", onde o nome do usuário que fez o RT aparece claramente como a fonte da informação). Assim, obtém-se algum tipo de valor (atenção e visibilidade) com um pequeno investimento de esforço (fazer o RT). Talvez por isso, conforme demonstram Romero et al (2010), poucos engajem-se em gerar informações originais, pois é possível obter visibilidade apenas através do repasse de informações. O retweet é, portanto, causa e consequência, parte de um balanço complexo entre o bem público e o privado, construído através do capital social.

\section{Referências bibliográficas}

ADAR, E.; ADAMIC, L. Tracking information epidemics in blogspace. In: Web Intelligence 2005, Compiegne, França, 2005.

BENKLER, Y. The Wealth of Networks. New Haven: Yale University Press, 2006. 
BERTOLINI, S.; BRAVO, G. Social capital, a multidimensional concept. 2004. Disponível em:

<http://web.archive.org/web/20030318075349/http://www.ex.ac.uk/shipss/politics/research/soci alcapital/other/bertolini.pdf>. Acesso em: 8 jun. 2008.

BOYD, d.; GOLDER, S.; LOTAN, G. Tweet, Tweet, Retweet: conversational aspects of retweeting on Twitter. In: HICSS-43. Kauai, HI: IEEE Press, 2010.

BURT, R. Structural Holes: The Social Structure of Competition. Cambridge, MA: Harvard University Press, 1992.

BURT, R. The Network Structure of Social Capital. In: SUTTON, R. and STAW, B. Research in Organizational Behavior, JAI Press, v. 22, , 2000.

CHA, M.; HADDADI, H.; BENEVENUTO, F.; GUMMADI, K. Measuring User Influence in Twitter: The Million Follower Fallacy. In: ICWSM, 2010.

COLEMAN, J. S. Social Capital and the Creation of Human Capital. American Journal of Sociology, n. 94, 1988, p. S95-S120.

GRANOVETTER, M. The Strenght of Weak Ties. American Journal of Sociology, n. 78, 1973, p. 1360-1380.

The Strenth of Weak Ties: Network Theory Revisited. Sociological Theory, v. 1, 1983, p. 203-233.

HONEYCUTT, C.; HERRING, S. Beyond microblogging: Conversation and collaboration via Twitter. HICSS-42. Los Alamitos, CA: IEEE Press, 2009.

HUBERMAN, B., ROMERO, D. \& WU, F. Social Networks that matter: Twitter under the microscope. First Monday, v. 14, n. 1,5 jan, 2009. Disponível em: <http://firstmonday.org/htbin/cgiwrap/bin/ojs/index.php/fm/article/view/2317/2063>. Acesso em: 20 jan. 2009.

JAVA, A.; SONG, X.; FININ, T.; TSENG, B. Why We Twitter: Understanding Microblogging Usage and Communities. In: 9th WEBKDD, 2007.

KOLLOCK, P. The economies of online cooperation: gifts and public goods in cyberspace. In: M. SMITH; P. KOLLOCK (ed.). Communities in cyberspace. Londres: Routledge, 1999.

LANHAM, R. The Economics of Attention. Chicago: University Of Chicago Press, 2006.

LIN, N. Social capital. A theory of social structure and action, Cambridge, Cambridge University Press, 2001.

PUTNAM, R. D. Bowling Alone. New York: Simon \& Schuster, 2000.

RECUERO, R. Redes sociais na Internet. Porto Alegre: Sulina, 2009.

RECUERO, R; ZAGO, G. Em busca das "redes que importam": redes sociais e capital social no Twitter. Líbero, São Paulo, v. 12, n. 24, p. 81-94, 2009. 
ROMERO, D.; GALUBA, W.; ASUR, S.; HUBERMAN, B. Influence and Passivity in Social Media. Social Science Research Network Working Paper Series, 2010.

SCOTT, J. Social Network Analysis. A Handbook. 2nd ed. London, UK: Sage Publications, 2000.

SUH B.; HONG, L.; PIROLLI, P; CHI, E. Want to be retweeted? Large scale analytics on factors impacting retweet in Twitter network. In: Proceedings of the IEEE Second International Conference on Social Computing (SocialCom), 2010, p. 177-184.

WASSERMAN, S; FAUST, K. Social Network Analysis. Methods and Applications. Cambridge, UK: Cambridge University Press, 1994.

WU, F.; HUBERMAN, B. Novelty and collective attention. Proc. Natl. Acad. Sci, v.104, b. 45, Estados Unidos, 2007. Disponível em: <http://www.pnas.org/content/104/45/17599.abstract>. Acesso em: 12 dez. 2011.

XIAO, W.; JIANG, Y.; ADAMIC, L. ARAÚJO, R.; MANU, R. Diffusion dynamics of games on online social networks. In: WOSN, 2010. 